\title{
Imaging aspects of cardiovascular disease at the cell and molecular level
}

\author{
Douglas J. Taatjes • Marilyn P. Wadsworth • \\ Anthony S. Quinn · Jacob H. Rand • \\ Edwin G. Bovill • Burton E. Sobel
}

Accepted: 15 May 2008 / Published online: 28 May 2008

(C) Springer-Verlag 2008

\begin{abstract}
Cell and molecular imaging has a long and distinguished history. Erythrocytes were visualized microscopically by van Leeuwenhoek in 1674, and microscope technology has evolved mightily since the first single-lens instruments, and now incorporates many types that do not use photons of light for image formation. The combination of these instruments with preparations stained with histochemical and immunohistochemical markers has revolutionized imaging by allowing the biochemical identification of components at subcellular resolution. The field of cardiovascular disease has benefited greatly from these advances for the characterization of disease etiologies. In this review, we will highlight and summarize the use of microscopy imaging systems, including light microscopy, electron microscopy, confocal scanning laser microscopy, laser scanning cytometry, laser microdissection, and atomic force microscopy in conjunction with a variety of histo-
\end{abstract}

D. J. Taatjes $(\bowtie) \cdot$ M. P. Wadsworth · A. S. Quinn · E. G. Bovill Department of Pathology, College of Medicine,

University of Vermont, 89 Beaumont Avenue,

Burlington, VT 05405, USA

e-mail: douglas.taatjes@uvm.edu

D. J. Taatjes · M. P. Wadsworth · A. S. Quinn

Microscopy Imaging Center,

College of Medicine, University of Vermont,

149 Beaumont Avenue, Burlington, VT 05405, USA

D. J. Taatjes · B. E. Sobel

Cardiovascular Research Institute,

University of Vermont, Colchester Research Facility,

208 South Park Drive, Colchester, VT 05446, USA

J. H. Rand

Department of Pathology, Montefiore Medical Center,

Albert Einstein College of Medicine, Bronx, NY 10467, USA chemical techniques in studies aimed at understanding mechanisms underlying cardiovascular diseases at the cell and molecular level.

Keywords Cardiovascular disease $\cdot$ Microscopy ·

Cytochemistry $\cdot$ Immunocytochemistry $\cdot$ Image analysis

\section{Introduction}

We have been developing novel procedures and utilizing microscopy-based imaging for many years to elucidate the pathogenesis of cardiovascular disease. The techniques have included wide-field light microscopy, fluorescence microscopy, confocal scanning laser microscopy, transmission electron microscopy and immunoelectron microscopy, atomic force microscopy, and laser scanning cytometry. Experimental models ranged from purified proteins, through cells to tissue samples, of both human and animal origin. This review will focus on these microscope-based techniques used in cardiovascular research. Non-invasive non-microscopy based imaging techniques, such as magnetic resonance imaging (MRI) and micro-SPECT/CT are beyond the scope of the present review, although we have briefly covered them previously (Sobel et al. 2003) as have others (Borg et al. 2005; Isobe et al. 2006; Mulder et al. 2006; Sanz and Fayad 2008). Similar to our earlier manuscript on the morphological and cytochemical determination of apoptosis (Taatjes et al. 2008), this review will highlight various areas of microscopy-based research in cardiovascular disease as promulgated through descriptions of the imaging systems, with emphasis on advances succeeding our previous brief review (Taatjes et al. 2001b). Although the pertinent literature is voluminous, we shall focus primarily on techniques employed by our own group. 
Omissions of citations to many other elegant publications are regrettable but unavoidable.

\section{Wide-field microscopy, confocal scanning laser microscopy, and computer-assisted image analysis}

The primary imaging tool since the seventeenth century has been the microscope. As has so often been the case with advances in biomedical research, self experimentation by pioneers was prominent. van Leeuwenhoek observed his own red blood corpuscles (erythrocytes) in 1674 with his simple self-built hand-held single-lens microscope (Dobell 1958). The introduction of chromatically corrected objective lenses in the 1800 s dramatically improved the performance of compound-lens microscopes and initiated finer detail studies of constituents in blood (Addison 18411842). However, given the enormous breadth of the cardiovascular disease field, by way of example, we will now restrict our focus to studies we have been involved with to highlight the role microscopy has played in investigating atherosclerotic lesion formation and the response of the myocardium to an ischemic event.

Atherosclerotic plaques are generally considered to be either: (1) biologically stable_characterized by a neointima replete with vascular smooth muscle cells and a thick fibrous cap, with a paucity of lipid and other cellular constituents; or (2) unstable (or vulnerable to rupture) - characterized as lipid-laden with a thin fibrous cap, relatively devoid of smooth muscle cells, and containing an abundance of macrophages (in the form of foam cells) and T-lymphocytes (Falk 1989). We have been developing methods over the past decade to clarify the nature of plaque formation, by focusing not on the conventional measurement of area, but rather on the composition of the lesion. To ensure standardization, we used well-characterized mouse models and followed the method of Paigen and colleagues (1987) imaging and analyzing corresponding $300 \mu \mathrm{m}$ areas at the level of the aortic sinuses. Initially, we demonstrated the effectiveness of using confocal microscopy to image thick cryostat sections from mouse aorta stained with both histochemical and fluorescent dyes (Taatjes et al. 2000). Two dyes conventionally used in transmitted bright field light microscopy, picrosirius red (collagen marker), and oil red $\mathrm{O}$ (lipid marker) were found to emit a fluorescence signal when excited by 568 and $647 \mathrm{~nm}$ laser light, respectively. We combined these stains with a fluorescent marker for cell nuclei (SYTOX Green), and an antibody directed against $\alpha$-smooth muscle actin followed by a fluorescently conjugated secondary antibody to identify smooth muscle cells. Using these markers, together with commercially available computer-assisted image analysis programs, we were able to determine the percentages of the lesions com- prising lipid, collagen, smooth muscle cells, and total cells, in addition to the size of the lesion. We subsequently performed a comparative plaque lesion analysis based upon age and gender in apolipoprotein $\mathrm{E}$ knockout mice $\left(\mathrm{ApoE}^{-/-}\right)$ (Wadsworth et al. 2002). Focusing on the components total cellularity, lipid, and collagen, a combination of transmitted bright field light microscopy (lipid), polarized light microscopy (collagen) and wide-field fluorescence microscopy (total cellularity) were used (Fig. 1). A comparison of lesion composition in 10- and 20-week-old male and female animals revealed a 2.5-fold increase in collagen composition in 20-week-old female animals compared with all other groups. Although the plaque cellularity trended toward a decrease with age of the animal, the lipid composition was unchanged. The results indicated that the imaging and analysis methods developed can detect age- and gender-dependent differences, even in a small cohort of animals. Indeed, in a subsequent study (Schneider et al. 2004), we found that overexpression of plasminogen activator inhibitor type-1 (PAI-1) in vascular smooth muscle cells (see section below on Laser scanning cytometry for more details on this study) resulted in decreased lesion cellularity, compared with that in control animals (Fig. 2). The precise methodological details of these methods have recently been published (Wadsworth et al. 2006).

We next used these newly developed lesion analysis methods to investigate whether insulin resistance alters atherogenesis in the proximal aorta (Clough et al. 2005). The composition of the lesions was characterized in $\mathrm{ApoE}^{-/-}$ mice and in mice in which insulin resistance was intensified by a concomitant heterozygous deficiency in insulin receptor substrate type $2\left(\operatorname{IRS}^{ \pm} \mathrm{ApoE}^{-/-}\right)$. Additionally, the effect of the insulin sensitizer pioglitazone on plaque composition was determined in $\operatorname{IRS} 2^{ \pm} \mathrm{ApoE}^{-/-}$mice. The results showed that the extent of the aortic intima occupied by lesion was significantly increased in the IRS2 ${ }^{ \pm} \mathrm{ApoE}^{-/-}$ compared with the ApoE ${ }^{-1-}$ mice. Treatment of $\mathrm{IRS} 2^{ \pm}$ $\mathrm{ApoE}^{-1-}$ mice with pioglitazone resulted in a decrease in both lipid content and cellularity in the neointima. Thus, genetically induced insulin resistance in dyslipidemic, atherogenic transgenic mice exacerbated the extent of vascular disease. Moreover, the attenuation of insulin resistance afforded by treatment with pioglitazone decreases the lipid and cellular content of atherosclerotic lesions, and thus may be capable of lessening the risk of vulnerable plaque rupture in patients with insulin resistance. Interestingly, in another study restricted to $\mathrm{ApoE}^{-1-}$ mice fed a high-fat diet (which themselves are slightly insulin resistant when fed a diet high in fat content), treatment with the insulin sensitizers troglitazone and rosiglitazone was observed to have had no effect on lesion size, lesion lipid content, and lesion cellularity as investigated by confocal scanning laser microscopy (Cefalu et al. 2004). 
Fig. 1 Demonstration of staining used to analyze the composition of atherosclerotic lesions in the aortas of C57B16 and ApoE knockout mice. a Oil red O staining of a section of aorta from a 20-week-old male C57B16 mouse shows essentially no lipid-containing lesion. Images from the aortas of 20week-old female ApoE knockout mice stained with oil red $\mathrm{O}$ to demonstrate lipid (b), SYTOX Green to stain nuclei as an indicator of cellularity (c), and Picrosirius red as to detect collagen (d). Image " $\mathrm{C}$ " was created by digitally stitching vessel segments together to represent an entire aorta in cross-section. Transmitted light brightfield microscopy (a, b), epi-fluorescence microscopy (c), and polarized light microscopy (d). The images were cropped and processed in Adobe PhotoShop to remove extraneous tissue to highlight the aorta. From Wadsworth et al. 2002
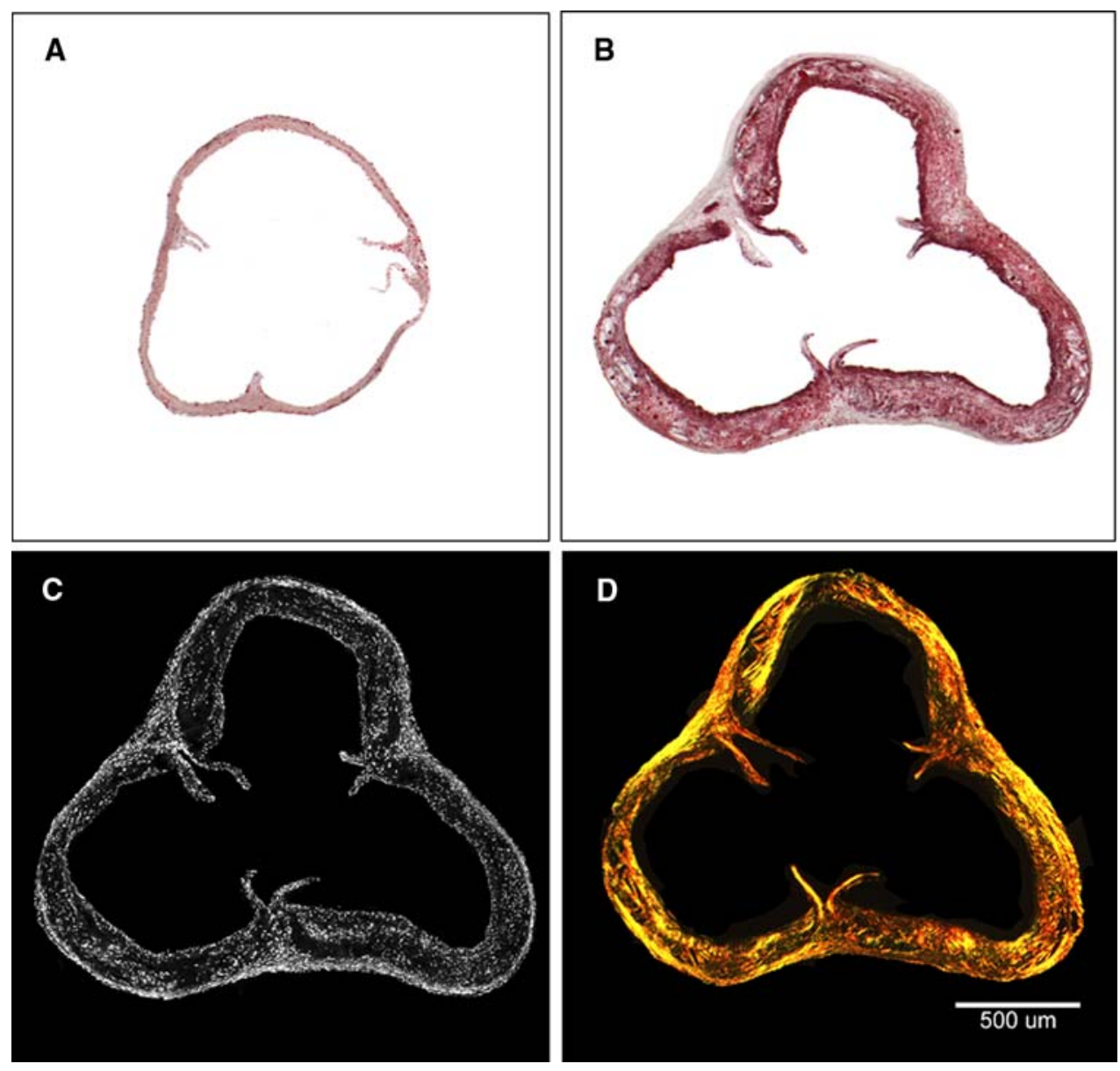

The imaging and analysis methods developed have recently been used to demonstrate that LDL receptor-deficient mice overexpressing Group V phospholipase $\mathrm{A}_{2}$ (an enzyme with potent hydrolytic activity towards lipoprotein particles) had a 2.7-fold increase in aortic root lesion area compared with that in control animals (Bostrom et al. 2007). This increased atherosclerotic lesion area was accompanied by a concomitant increase in lesion collagen content.

These examples were provided to illustrate the utility of the imaging and analysis methods we have been using in our studies and continue to develop. Currently, we are working on methods, utilizing state-of-the-art confocal scanning laser microscopy to identify all of the major components of an atherosclerotic lesion in a single section. Previously, we were limited to the three imaging channels available on our confocal microscope, but newer systems allow imaging of eight or more channels from one tissue section. An example of this work in progress is shown in Fig. 3.

The imaging techniques developed have enabled us to evaluate the response of mouse myocardium to transitory coronary artery ligation. We have found that PAI-1 knockout animals subjected to myocardial infarction induced by coronary artery ligation exhibit massive infarcts with a greater proportion of CD45-positive inflammatory cells compared with that in control animals (Tarikuz Zaman et al. 2007). Numerous types of cell death have been described in diverse tissues and organs. In the case of the heart subjected to ischemia, the predominant form is oncotic cell death characterized by preceding cell swelling, mitochondrial disruption, and ultimately coagulative necrosis. For the past 50 years, much clinical cardiovascular investigation has focused on limitation of oncotic cell death by enhancement of myocardial perfusion, reduction of myocardial oxygen requirements, or metabolic protection of the heart subjected to ischemia in an effort to salvage and preserve jeopardized myocardium. Prognosis after myocardial infarction is linked closely to the extent of infarction sustained, and accordingly, interventions targeting these processes have led to a substantial improvement in outcome. In fact, many believe that further refinements addressing these specific processes will have little additive impact on survival and reduction of morbidity in part because so much has been achieved already, and in part because further limitation of oncotic cell death is unlikely to be of substantial biological significance. Accordingly, investigators have focused their attention increasingly on the possible role of another form of myocardial cell death, 
Fig. 2 Illustration of the difference in atherosclerotic lesion cellularity between a 20 weekold ApoE ${ }^{-/-}$mouse (a) and a 20 week-old $\mathrm{ApoE}^{-/-}$PAI-1 ${ }^{+}$ mouse (b). Cryostat sections were stained with DAPI and viewed by conventional widefield fluorescence microscopy using a $10 \times$ objective lens. Captured images were digitally stitched together and cropped to display the complete segment of aorta. Note the areas in "B" devoid of cellularity (arrows). c Results of qualitative and quantitative evaluation of lesion cellularity demonstrating the decreased lesion cellularity of $\mathrm{ApoE}^{-1-}$ PAI- $1^{+}$animals compared with $\mathrm{ApoE}^{-/-}$animals. Scale bar $100 \mu \mathrm{m}$. c From Schneider et al. 2004


programmed cell death or apoptosis, as a contributor to overall cardiomyocyte cell death early after ischemic insults following persistent coronary occlusion in patients treated with interventions designed to induce recanalization as promptly as possible.

If apoptosis plays a major role in total cell death consequent to ischemia, i.e., its extent and distribution are substantial, it is possible that anti-apoptotic interventions could result in further increments in survival and reduction of morbidity after acute coronary syndromes precipitated by coronary occlusion. Conversely, if the magnitude and distribution of apoptosis in myocardium subjected to ischemic insults are modest, it is unlikely that therapeutic interventions targeting apoptosis will confer substantial clinical benefit (Binbrek et al. 2007; Sobel et al. 2008). In view of these considerations, quantification of cardiomyocyte apoptosis and its temporal evolution after the onset of an ischemic insult is needed. Unfortunately, it has been difficult to accomplish such quantification in part because of methodologic limitations. To determine whether apoptotic cells are prominent in the heart after an ischemic event we have developed a novel dual staining procedure utilizing antibodies against cleaved caspase- 3 and single-stranded DNA, imaged by confocal scanning laser microscopy. With the use of these dual methods and thymus from dexamethasone-treated mice as a positive control, we found that apoptosis was scanty in the myocardium of mice subjected to persistent coronary artery ligation for three days (Taatjes et al. 2007, 2008). In continuation of these studies, we are now examining tissue harvested at diverse intervals after coronary occlusion with and without recanalization, and with the use of additional imaging methods.

\section{Laser scanning cytometry}

Laser scanning cytometry (LSC) combines features of flow cytometry with microscopy-based imaging (Kamentsky and Kamentsky 1991; Kamentsky et al. 1997; Taatjes et al. 2001a; Pozarowski et al. 2006; Harnett 2007). Fluorescently tagged cells (or tissue sections) are affixed to a solid support (glass slide) and raster scanned via an $x, y$ scanning 


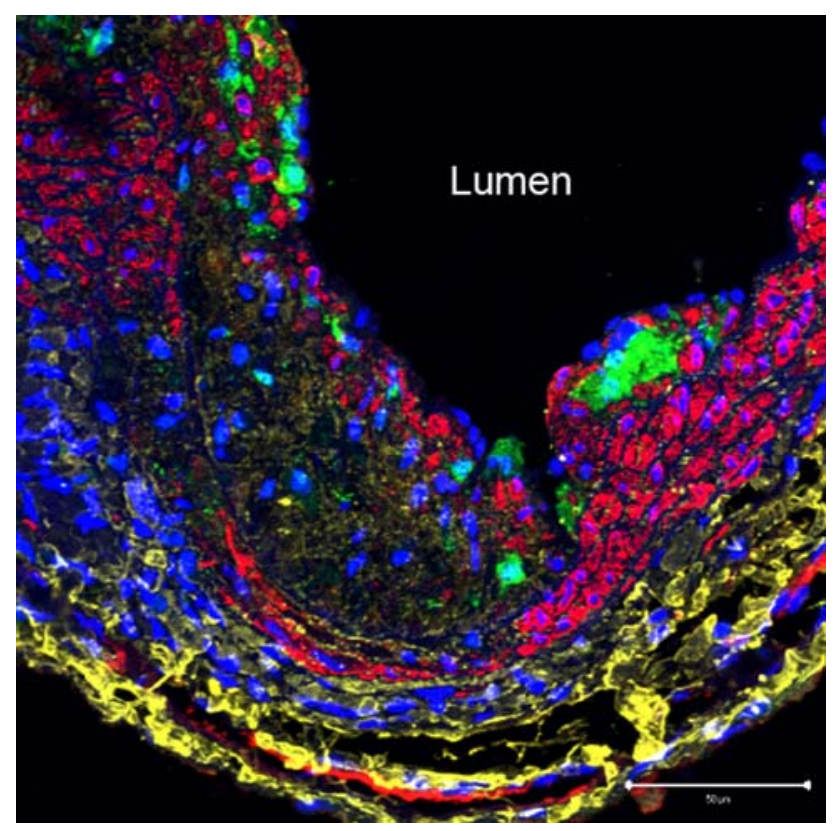

Fig. 3 Paraffin section of aorta from an 18 week-old male $\mathrm{ApoE}^{-/-}$ mouse fed a high fat diet and stained with DAPI (blue) to label nuclei, rat anti-mouse Mac-2 (green) for macrophages, mouse anti- $\alpha$-smooth muscle actin clone 1A4 (red) and rabbit anti-collagen type III (yellow). The section was imaged on a Zeiss LSM510 META confocal scanning laser microscope. A Z-series was collected with a $\times 40$ (NA 1.4) objective lens and projected. Scale bar $50 \mu \mathrm{m}$

stage below a fixed laser source. The acquired data are in the form of scatterplots and histograms, and are comparable to those obtained by flow cytometry. Since the specimen is attached to a glass slide, regions of interest on a scatterplot can be identified, and the cells visually relocated and examined, affording an advantage over flow cytometry.

We have used the LSC to assess smooth muscle cell migration in an in vitro assay. Vulnerable atherosclerotic plaques exhibit a paucity of smooth muscle cells in the cap, while maintaining a large lipid content. Accordingly, attenuated migration of smooth muscle cells from the tunica media into the neointima during lesion development may be a factor in plaque rupture (Sobel 1999a, b; Sobel et al. 2003). In many cell types, the balance between cell surface plasminogen activator activity and its inhibition by plasminogen activator inhibitor type 1 (PAI-1) modulates migration. We tested this hypothesis by investigating the migration of smooth muscle cells isolated from vessel walls of mice overexpressing PAI-1 in vessel walls crossed onto an Apo $\mathrm{E}^{-1-}$ mouse line (Schneider et al. 2004). Smooth muscle cells explanted from PAI-1 overexpressing animals and from control animals were plated onto a Matrigelcoated upper surface of a dual chambered Biocoat insert system. A chemoatractant was loaded into the lower chamber, and migration was assessed $20 \mathrm{~h}$ later. After cells from the upper chamber were scraped away, those from the lower chamber were fixed and stained with propidium iodide, and the chamber membrane separated from the insert and mounted on a glass slide. The slides were then evaluated by LSC, and scanned cells randomly selected from the scatterplots were visually relocated by the microscope and automated stage to confirm their identity as whole cells. The results showed that fewer cells from the PAI-1 overexpressing transgenic animals migrated to the lower chamber compared with those explanted from the negative control animals. The major advantages of LSC in this experiment were the ability to use automated rapid scanning to assess the entire area of the lower membrane in a quantitative manner, and to visually inspect the counted cells in order to eliminate false-positives attributable to cellular debris constituents.

\section{Laser microdissection}

Laser microdissection (LMD) is a microscope-based technique that uses ultraviolet or infrared lasers to selectively procure identified cells of interest from a heterogeneous tissue section for subsequent molecular analysis (EmmertBuck et al. 1996; Taatjes et al. 2001a; Eltoum et al. 2002; Bova et al. 2005; Pinzani et al. 2006). This technique can be combined with rapid immunostaining protocols for precise identification of targeted cells (Fend et al. 1999). The term laser capture microdissection is usually employed to describe the use of a capture film with an infrared laser, whereas the more generic term laser microdissection refers to all microdissection techniques. Whenever possible, LMD is employed on unfixed cryostat sections, although more recently formalin-fixed and routinely paraffin embedded sections have been used. The difficult aspect of LMD is preserving delicate RNA molecules throughout the required processing steps, which has lead to suggested protocols involving unfixed frozen sections (Goldsworthy et al. 1999; Morrogh et al. 2007).

Laser microdissection is a useful technique for investigating gene expression in atherosclerotic plaque lesions, which are composed of a variety of cell types and extracellular matrix components. Trogan and colleagues (2002) used LMD to isolate macrophages (identified by immunostaining with anti-CD68 antibody) from atherosclerotic plaques from Apo $\mathrm{E}^{-/-}$mice. They isolated purified populations of macrophages, as indicated by an enrichment of macrophage-specific RNA by RT-PCR, without contamination from other cells in the lesions, such as smooth muscle cells. Stolle et al. (2004) used LCM techniques to investigate gene expression in smooth muscle cells in human coronary artery sections. Using markers to distinguish contractile from synthetic phenotype smooth muscle cells, they were able to show that cells isolated from the intima 
predominantly displayed a synthetic phenotype, whereas cells from the media expressed high RNA levels for markers of contractile smooth muscle cells. They concluded that the data achieved with LCM combined with RT-PCR are comparable to those obtained from more time consuming fluorescence in situ hybridization techniques. It seems reasonable to assume that LMD will continue to be a valuable technique for the investigation of gene (and protein) expression in a variety of cardiovascular disease investigations.

Bobryshev (2005) used LCM in an interesting combination with high-resolution transmission electron microscopy (please see below) to examine the immunolocalization of oxidized low-density lipoproteins from LCM captured cells. Cryostat sections from immunolabeled atherosclerotic plaques were subjected to LCM, and the microdissected cells were further processed for electron microscopy. When imaged by electron microscopy, the immunoreactivity for oxidized low-density lipoproteins was observed in microvesicles along the border of lipid droplets in macrophage foam cells.

\section{Transmission electron microscopy}

The ability of the transmission electron microscope to provide high-resolution ultrastructural details of cells and tissues in health and disease was recognized by some early after its introduction in the 1930s (see Ruska 1980 for a discussion). In an Appendix in Ruska's book, a professional assessment (written on November 2, 1936 by Professor R. Siebeck, Director of the First Medical University for Charity in Berlin) addressed the possible advances in medical science afforded by the introduction of the electron microscope: "Assuming that an improvement of resolving power is established to the point where one could recognize details ten times smaller than before and making a further assumption that suitable preparation methods can be developed, which seems to me feasible, there is over the total range of medicine the possibility of the solution of an abundance of old and new problems. I am of the opinion, that fine structures in no way stop short at the resolution limit of the light microscope." After describing some perceived uses of the electron microscope in areas such as cell membranes, fibers, nerves, blood cells, cytoplasm and nucleus, Siebeck went on to assert: "It is clear, that with a precise investigation of such things our theoretical knowledge would be appreciably furthered. However, this would in no way exhaust the significance of the electron microscope; one can expect with even more confidence that investigations of the blood, spinal fluids etc. would enable one to see new specific pathological variations of the above mentioned structures." These prescient words mentioned the require- ment for improved cell and tissue preparation methods before the electron microscope could prove to be a valuable method for the investigation of cells and tissues. Indeed, it was the introduction of specialized chemical fixatives [such as glutaraldehyde by Sabatini (1963)] and ultrathin sectioning techniques (thanks to the introduction of the Porter Blum ultramicrotome in 1953) that provided the advances necessary for the fulfillment of Siebeck's prognostication.

In two early reports, prior to the introduction of glutaraldehyde fixative and therefore using direct primary fixation in buffered osmium tetroxide, Bryant et al. (1958) and Caulfield and Klionsky (1959) characterized the ultrastructural features of ischemic myocardium in rats and rabbits, respectively. Their images highlighted the structural changes occurring to mitochondria, myofibrils, and the nucleus, now known to be morphological hallmarks of oncotic cell death of ischemic myocardium (Fig. 4). Since this time, transmission electron microscopy has been in continuous use in studies of cardiovascular disease whenever ultrastructural detail is required. Electron microscopy is still considered the "gold standard" with respect to the determination of apoptosis as noted previously (Taatjes et al. 2008), and several studies looking for apoptosis in the heart following an ischemic event, or treatment to induce apoptosis have been published (Ohno et al. 1998; Hayakawa et al. 2002; Takemura and Fujiwara 2006; Abbate et al. 2007). Although electron microscopic images can provide amazing structural detail and resolution, they remain subject to observer interpretation. This subjectivity can to some extent be mitigated by combining the high-resolution imaging of electron microscopy with the biochemical

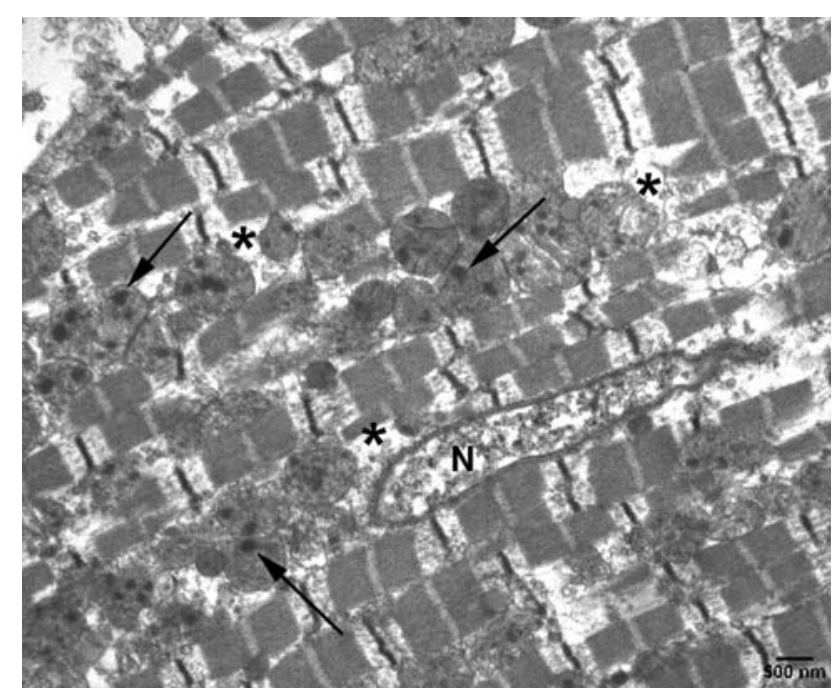

Fig. 4 Transmission electron micrograph of thin section from mouse myocardium subjected to $4 \mathrm{~h}$ of left coronary artery ligation, followed by $24 \mathrm{~h}$ of reperfusion. Note the general ischemic appearance of the tissue: disrupted nucleus $(N)$, cytoplasmic vacancies (asterisks), and electron dense deposits (arrows) in the mitochondria 
specificity of immunolabeling techniques. In particular, the combination of specific antibody probes with electron dense markers has revolutionized the field of electron microscopy (see for instance Plattner 1989).

\section{Immunoelectron microscopy}

A variety of electron dense labels, including peroxidase, ferritin, colloidal gold, and more recently quantum dots, have been used as markers in electron microscopy. Their use in conjunction with highly specific antibodies facilitates precise ultrastructural localization of antigens within tissues and cells. For instance, we immunolocalized PAI-1 on ultrathin cryosections of smooth muscle cells from morphologically normal and atherosclerotic human arteries (as well as explanted cultured smooth muscle cells) (Taatjes et al. 1997b). We found that in smooth muscle cells displaying a contractile phenotype, the PAI-1 immunoreactivity (as revealed by colloidal gold particle label) was predominantly associated with contractile filaments, whereas in smooth muscle cells presenting a synthetic phenotype it was additionally associated with elements of the rough endoplasmic reticulum. Smooth muscle cell identification was established by immunostaining with an antibody against $\alpha$-smooth muscle actin.

A promising approach for future investigations of cardiovascular disease is correlative light and electron microscopy using quantum dots (Nisman et al. 2004; Giepmans et al. 2005; Storch et al. 2007). Quantum dots are semi-conductor nanocrystals possessing the unique property of being both fluorescent and electron dense. The use of these probes would allow for a wide field of view for general tissue or cellular distribution by confocal or wide-field fluorescence microscopy, followed by high-resolution component subcellular localization by transmission electron microscopy. We believe that the power afforded by the correlative combination of these two techniques will provide the means to assess immunolocalization patterns of antigens in a variety of cardiovascular disease settings.

\section{Atomic force microscopy}

The atomic force microscope is a member of the scanning probe microscope family (Binnig et al. 1986). It features a tactile sensing system, in which a silicon or silicon nitride probe is attached to the end of a flexible cantilever and raster scanned in $x$ and $y$ directions across a specimen through the activity of a piezoelectric tube to which the cantilever assembly is mounted (Montigny et al. 2006). A laser beam is focused onto the surface of the cantilever, and the reflected beam is directed up to a four quadrant photodiode, that converts laser movement on the surface into a measur- able electrical voltage change. The resulting voltage change is then translated via computer interface into height and amplitude information about the specimen. The overall complexity of the system is in stark contrast to the simplicity of specimen preparation; purified molecules (such as proteins, lipids, and nucleic acids), fixed or unfixed cells grown or deposited onto glass coverslips can be readily imaged by atomic force microscopy (AFM) without further processing. Moreover, labeling with colloidal gold particles can be incorporated into an AFM immunostaining protocol, allowing cellular areas of interest to be identified by the colloidal gold marker (Cho et al. 2002), and then imaged at high resolution by AFM.

Atomic force microscopy has been used in a variety of research areas in cardiovascular disease, ranging from analysis of individual protein molecules to imaging portions of intact arterial endothelial surfaces. Fibrinogen is a large (approximately $340 \mathrm{kDa}$ ) multidimensional glycoprotein involved in important cardiovascular functions such as coagulation. As a first step towards understanding its role in the clotting mechanism, we deposited purified unfixed human fibrinogen onto poly-L-lysine-coated freshly cleaved muscovite mica disks and added $15 \mathrm{~nm}$ colloidal gold particles to the fibrinogen preparation to serve as an internal measurement standard. The preparation was then imaged in fluid (buffer) using a Digital Instruments BioScope operating in TappingMode (Taatjes et al. 1997a). The fibrinogen molecules were observed to be of slightly curvilinear appearance with two or three nodular domains, with a nominal height of $2.4-4.1 \mathrm{~nm}$. Similar AFM results were reported by Marchant and co-workers (Marchant et al. 1997; Sit and Marchant 1999). The structural appearance of the native fibrinogen molecule in fluid delineated by AFM was consistent with the excellent images obtained on fixed and dried specimens by transmission electron microscopy (Hall and Slayter 1959) and highlights the synergistic approach afforded by these two imaging modalities.

In a very early AFM study, Drake and colleagues (1989) presented a series of ten images revealing the polymerization of fibrin molecules in fluid, thereby illustrating the potential of this technology for the molecular-level imaging of biological constituents and processes. Moreover, as its name implies, the atomic force microscope can also be used to measure forces at the atomic level. An ingenious use of the atomic force microscope was demonstrated by Liu and colleagues (2006), who used an AFM tip to stretch single fibrin fibers suspended across a channel to measure their mechanical properties. They found that uncross-linked fibers could be stretched 2.2 times their length, whereas cross-linked fibers could be stretched over 2.8 times their length; both types of fibers recovered without permanent damage. Their data also suggested that the marked extensibility and elasticity of individual fibrin fibers may influence 
the mechanical properties of in vivo clots. To begin to investigate these clot mechanical properties, Weisel and colleagues have simplified the clot system by measuring the unfolding properties of fibrinogen domains from singlestranded fibrinogen polymers using single-molecule AFM (Brown et al. 2007; Weisel 2008). The results from these high precision studies suggest that the $\alpha$-helical coiled-coils unfold first, serving as a molecular component of clot resistance to degradation.

Proceeding from individual fibers to intact cells, others characterized viscoelastic properties of human platelets by measuring force curves as a function of position of the tip with respect to the surface of the cell (Radmacher et al. 1996). They found that depending upon the location on the cell, the elastic moduli ranged between 1 and $50 \mathrm{kPa}$. This measurement of elastic stiffness reflects the state of the underlying cytoskeleton that undergoes rapid changes and reorganization as the platelet reacts to physiologic stimuli.

From a cardiovascular clinical research standpoint, we have used AFM to investigate molecular mechanisms involved in the anti-phospholipid (aPL) syndrome (Rand et al. 2003). aPL syndrome is an enigmatic autoimmune disease in which patients who have antibodies against phospholipid/protein cofactor complexes-primarily a protein named $\beta 2$-glycoprotein I ( $\beta 2 \mathrm{GPI}$ ) - are predisposed to systemic vascular thrombosis and recurrent pregnancy losses (Rand and Wu 1999). Placental trophoblasts and endothelial cells highly express an anticoagulant protein, annexin A5, which binds to, and crystallizes over, thrombogenic phospholipids that are expressed on the apical membranes of these cells. These crystals act as potent anticoagulants by shielding the phospholipids from availability for coagulation reactions. We hypothesized that autoantibodies in aPL syndrome patients disrupt this annexin A5 anticoagulant shield exposing the underlying cell membrane as a potential procoagulant site (Rand and Wu 1999). To test this hypothesis, we formed two-dimensional crystals composed of annexin A5 on planar phospholipid-covered mica, and then exposed this preparation to $\beta 2 \mathrm{GPI}$, together with aPL monoclonal antibodies that were derived from patients (Rand et al. 2003). During temporal imaging of the buffercoated preparation by AFM, disruptions in the annexin A5 crystal were observed to various extents with the different monoclonal antibodies applied (Fig. 5). These morphological observations, supporting the hypothesis that aPL antibodies can disrupt annexin A5 binding to phospholipid bilayers were only attainable through the use of a high-resolution temporal imaging modality like AFM.

The antimalarial drug hydroxychloroquine (HCQ) which is widely used as an immunosuppressive agent in autoimmune disorders has, in epidemiologic studies of patients with systemic lupus erythematosus, been associated with reduction of the incidence of thrombosis. The drug has also been shown to reduce thrombus size in a murine model of aPL syndrome. The mechanism of this apparent antithrombotic effect has not been elucidated and has been attributed to the immunosuppressive properties of the drug or to its possible inhibitory effects on platelet function. We recently investigated whether HCQ might directly affect the formation of aPL IgG- $\beta 2$ GPI complexes on planar phospholipid bilayers (Rand et al. 2008). Imaging of $\mathrm{mAb}$ aPL IgG$\beta 2$ GPI complexes in fluid by AFM revealed that addition of HCQ resulted in a marked attrition of the complexes attached to phospholipid bilayers. Due to the quantitative nature of AFM (at least in the $Z$ dimension), the effect of HCQ on the maximal height of the aPL IgG- $\beta 2$ GPI complexes could be determined. These results, together with others that are described in that reference, suggest that since HCQ reduces the binding of aPL IgG- $\beta 2$ GPI complexes to phospholipid membranes, it might serve as an effective pharmacological agent targeting a step in the disease process that is earlier than the activation of coagulation reactions. These data raise the possibility of treatments that target formation of aPL antibody- $\beta 2 \mathrm{GPI}$ complexes rather than the current treatments that are based upon anticoagulant therapies-an especially exciting possibility since anticoagulant therapies are fraught with the risk of hemorrhagic complications.

A goal of our current endeavors in this area is to expand our AFM studies from assessment of purified proteins and lipids to assessment of cultured cells and ultimately tissues. The ability to image endothelial cells in their normal tissue/ vascular organization will allow us to investigate molecular mechanisms involved in the aPL syndrome, as well as other vascular diseases, in an in vivo-type setting. These types of tissue studies with the atomic force microscope are not trivial, necessitating the introduction of novel means to adhere tissues to a solid support for artifact-free imaging. Reichlin and colleagues (2005) have begun to approach this issue, and have developed a custom-made holder to secure pieces of artery tissue for AFM observation. Their modifications have yielded excellent quality images of the endothelial surface from intact coronary artery samples, and offer the possibility that further studies on native arterial tissues, including both imaging and force mode will provide new insights into the molecular mechanisms of vascular diseases.

\section{Conclusions}

In this brief and selective review, we have considered microscopy-based imaging techniques currently in use in the investigation of cardiovascular disease. All of these imaging techniques can be used in conjunction with histochemical and immunohistochemical methodologies to enhance the precise determination and identification of 

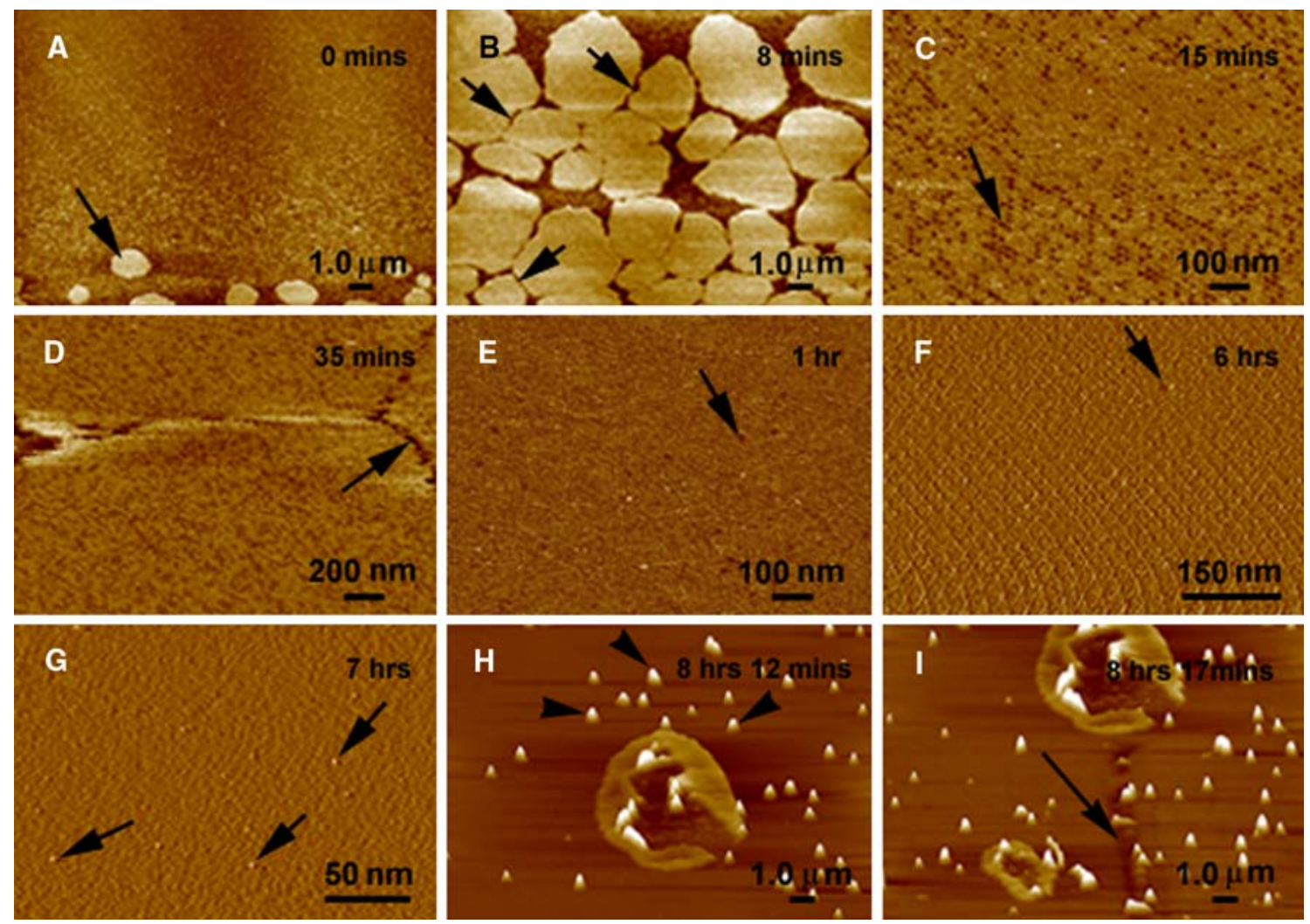

Fig. 5 Temporal sequential effects of plasma protein $\beta 2$ GPI and aPL $\mathrm{mAb}$ IS3 on annexin A5 crystal structure. AFM images from a dynamic fluid tapping mode imaging experiment showing the effect of IS3 (h and i) on a pre-formed annexin A5 crystalline lattice (a-g). Images (a-f) demonstrate the dynamic formation of an annexin A5 $(40 \mu \mathrm{g} / \mathrm{ml})$ 2-D crystal lattice on a planar phospholipid model membrane on muscovite mica. a At approximately one hour after adding annexin A5, (time zero) a 'pebbled' surface, indicating a primary conformational surface reaction, and forming annexin A5 crystal (arrow) lattice are seen. b Appearance of large and small irregular furrows (arrows) between coalescing annexin A5 lattices. Higher magnification (c) shows vacancies (arrow; small black holes) indicating incomplete 2D annexin A5 crystal lattice formation. Image (d) shows further diminution of vacancies and closing of furrows (arrow). Continual imaging (e and $\mathbf{f}$ ) showing very few vacancies (arrow) remaining. Image (g) shows elevated nodules (arrows), presumably $\beta 2 \mathrm{GPI}$ aggregates. The addition (at $40 \mathrm{~min}$ ) of $\beta 2 \mathrm{GPI}(15 \mu \mathrm{g} / \mathrm{ml})$ alone has no discernible effect on the integrity of the preformed crystalline lattice as observed at higher magnifications using height (e) and amplitude (f and g) imaging. On the subsequent addition (at $6 \mathrm{~h} 40 \mathrm{~min})$ of $\mathrm{mAb}$ IS3 $(80 \mu \mathrm{g} / \mathrm{ml})$, elevated globular structures, presumably antibody-antigen complexes (arrowheads) and circular deformities appeared, indicating intercalation, disruption and initial disintegration of the annexin A5 crystal lattice as seen in images (h) and (i). In image (i) an $x, y$ offset shows further extent of early stage reaction including furrow (elongated arrow) reappearance. Height images $(\mathbf{a}-\mathbf{e}, \mathbf{h}$ and $\mathbf{i})$ processed with third order flatten and erase scan line. Amplitude images $(\mathbf{f}, \mathbf{g})$ processed with $1 \times$ convolution. Original magnifications: $20 \mu \mathrm{m} \times 20 \mu \mathrm{m}$ scan $(\mathbf{a}, \mathbf{b}, \mathbf{h}, \mathbf{i})$; $2 \mu \mathrm{m}(\mathbf{d}) ; 1 \mu \mathrm{m}(\mathbf{c}, \mathbf{d}) ; 500 \mathrm{~nm}(\mathbf{f}, \mathbf{g})$. Displayed image $(\mathbf{g})$ is a zoomed image of $250 \mathrm{~nm} \times 250 \mathrm{~nm}$. All images are $3 \mathrm{D}$ view with $45^{\circ}$ pitch and zero rotation

2007; Rust et al. 2006; Scherer 2006; Rice 2007; Evanko 2008; Huang et al. 2008; Shroff et al. 2008) are shattering the conventional "diffraction limited" resolution barrier described by Abbe in the late 1800s (Brocksch 2005), portending exciting advances for the 100th Anniversary issue of the journal.

\section{References}

Abbate A, De Falco M, Morales C, Gelpi R, Prisco M, De Luca A, Palleiro J, Fedele V, Feroce F, Baldi F, Vetrovec GW, Baldi A (2007) Electron microscopy characterization of cardiomyocyte apoptosis in ischemic heart disease. Int J Cardiol 114:118-120

(Egner and Hell 2005; Betzig et al. 2006; Hess et al. 2006, 
Addison W (1841-1842) On the colourless corpuscles and on the molecules and cytoblasts in the blood. Lond Med Gaz NS 30:144-148

Betzig E, Patterson GH, Sougrat R, Lindwasser OW, Olenych S, Bonifacino JS, Davidson MW, Lippincott-Schwartz J, Hess HF (2006) Imaging intracellular fluorescent proteins at nanometer resolution. Science 313:1642-1645

Binbrek AS, Mittal B, Rao KNS, Sobel BE (2007) The potential of erythropoietin for conferring cardioprotection complementing reperfusion. Coron Artery Dis 18:583-585

Binnig G, Quate CF, Gerber C (1986) Atomic force microscope. Phys Rev Lett 56:930-933

Bobryshev YV (2005) Intracellular localization of oxidized low-density lipoproteins in atherosclerotic plaque cells revealed by electron microscopy combined with laser capture microdissection. J Histochem Cytochem 53:793-797

Borg TK, Stewart JA Jr, Sutton MA (2005) Imaging the cardiovascular system: seeing is believing. Microsc Microanal 11:189-199

Bostrom MA, Boyanovsky BB, Jordan CT, Wadsworth MP, Taatjes DJ, de Beer FC, Webb NR (2007) Group V secretory phospholipase $\mathrm{A}_{2}$ promotes atherosclerosis. Evidence from genetically altered mice. Arterioscler Thromb Vasc Biol 27:600-606

Bova GS, Eltoum IA, Kiernan JA, Siegal GP, Frost AR, Best CJM, Gillespie JW, Su GH, Emmert-Buck MR (2005) Optimal molecular profiling of tissue and tissue components. Defining the best processing and microdissection methods for biomedical applications. Mol Biotechnol 29:119-152

Brocksch D (ed) (2005) In memory of Ernst Abbe. Innovation, The Magazine from Carl Zeiss, vol 15, pp 3-23

Brown AEX, Litvinov RI, Discher DE, Weisel JW (2007) Forced unfolding of coiled-coils in fibrinogen by single-molecule AFM. Biophys J 92:L39-L41

Bryant RE, Thomas WA, O’Neal RM (1958) An electron microscopic study of myocardial ischemia in the rat. Circ Res 6:699-709

Caulfield J, Klionsky B (1959) Myocardial ischemia and early infarction: an electron microscopic study. Am J Pathol 35:489-523

Cefalu WT, Wang ZQ, Schneider DJ, Absher PM, Baldor LC, Taatjes DJ, Sobel BE (2004) Effects of insulin sensitizers on plaque vulnerability associated with elevated lipid content in atheroma in ApoE-knockout mice. Acta Diabetol 41:25-31

Cho S-J, Quinn AS, Stromer MH, Dash S, Cho J, Taatjes DJ, Jena BP (2002) Structure and dynamics of the fusion pore in live cells. Cell Biol Int 26:35-42

Clough MH, Schneider DJ, Sobel BE, White MF, Wadsworth MP, Taatjes DJ (2005) Attenuation of accumulation of neointimal lipid by pioglitazone in mice genetically deficient in insulin receptor substrate-2 and apolipoprotein E. J Histochem Cytochem 53:603-610

Dobell C (1958) Antony van Leeuwenhoek and his "little animals". Russell and Russell, New York

Drake B, Prater CB, Weisenhorn AL, Gould SA, Albrecht TR, Quate CF, Cannell DS, Hansma HG, Hansma PK (1989) Imaging crystals, polymers, and processes in water with the atomic force microscope. Science 243:1586-1589

Egner A, Hell SW (2005) Fluorescence microscopy with super-resolved optical sections. Trends Cell Biol 15:205-215

Eltoum IA, Siegal GP, Frost AR (2002) Microdissection of histologic sections: past, present and future. Adv Anat Pathol 9:316-322

Emmert-Buck MR, Bonner RF, Smith PD, Chuaqui RF, Zhuang Z, Goldstein SR, Weiss RA, Liotta LA (1996) Laser capture microdissection. Science 274:998-1001

Evanko D (2008) Seeing fluorescence at super-resolution. Nature Meth $5: 22$

Falk E (1989) Morphologic features of unstable atherothrombotic plaques underlying acute coronary syndromes. Am J Cardiol 63:114E-120E

Fend F, Emmert-Buck MR, Chuaqui R, Cole K, Lee J, Liotta LA, Raffeld M (1999) Immuno-LCM: laser capture microdissection of immunostained frozen sections for mRNA analysis. Am J Pathol 154:61-66

Giepmans BNG, Deerinck TJ, Smarr BL, Jones YZ, Ellisman MH (2005) Correlated light and electron microscopic imaging of multiple endogenous proteins using Quantum dots. Nat Meth 2:743749

Goldsworthy SM, Stockton PS, Trempus CS, Foley JF, Maronpot RR (1999) Effects of fixation on RNA extraction and amplification from laser capture microdissected tissue. Mol Carcinogen 25:8691

Hall CE, Slayter HS (1959) The fibrinogen molecule: Its size, shape and mode of polymerization. J Biophys Biochem Cytol 5:11-16

Harnett MM (2007) Laser scanning cytometry: understanding the immune system in situ. Nat Rev 7:897-904

Hayakawa K, Takemura G, Koda M, Kawase Y, Maruyama R, Li Y, Minatoguchi S, Fujiwara T, Fujiwara H (2002) Sensitivity to apoptosis signal, clearance rate, and ultrastructure of Fas ligandinduced apoptosis in in vivo adult cardiac cells. Circulation 105:3039-3045

Hess ST, Girirajan TPK, Mason MD (2006) Ultra-high resolution imaging by fluorescence photoactivation localization microscopy. Biophys J 91:4258-4272

Hess ST, Gould TJ, Gudheti MV, Maas SA, Mills KD, Zimmerberg J (2007) Dynamic clustered distribution of hemagglutinin resolved at $40 \mathrm{~nm}$ in living cell membranes discriminates between raft theories. Proc Natl Acad Sci (USA) 104:17370-17375

Huang B, Wang W, Bates M, Zhuang X (2008) Three-dimensional super-resolution imaging by stochastic optical reconstruction microscopy. Science 319:810-813

Isobe S, Tsimikas S, Zhou J, Fujimoto S, Sarai M, Branks MJ, Fujimoto A, Hofstra L, Reutelingsperger CP, Murohara T, Virmani R, Kolodgie FD, Narula N, Petrov A, Narula J (2006) Noninvasive imaging of atherosclerotic lesions in apolipoprotein E-deficient and low-density-lipoprotein receptor-deficient mice with annexin A5. J Nucl Med 47:1497-1505

Kamentsky LA, Burger DE, Gershman RJ, Kamentsky LD, Luther E (1997) Slide-based laser scanning cytometry. Acta Cytol 41:123143

Kamentsky LA, Kamentsky LD (1991) Microscope-based multiparameter laser scanning cytometer yielding data comparable to flow cytometry data. Cytometry 12:381-387

Liu W, Jawerth LM, Sparks EA, Falvo MR, Hantgan RR, Superfine R, Lord ST, Guthold M (2006) Fibrin fibers have extraordinary extensibility and elasticity. Science 313:684

Marchant RE, Barb MD, Shainoff JR, Eppell SJ, Wilson DL, Siedlecki CA (1997) Three dimensional structure of human fibrinogen under aqueous conditions visualized by atomic force microscopy. Thromb Haemost 77:1048-1051

Montigny WJ, Quinn AS, Wu X-X, Bovill EG, Rand JH, Taatjes DJ (2006) Atomic force microscopy in the study of macromolecular interactions in hemostasis and thrombosis: utility for investigation of the antiphospholipid syndrome. In: Jena BJ, Horber JKH (eds) Force microscopy: applications in biology and medicine. Wiley, Hoboken, pp 267-286

Morrogh M, Olvera N, Bogomolniy F, Borgen PI, King TA (2007) Tissue preparation for laser capture microdissection and RNA extraction from fresh frozen breast tissue. BioTechniques 43:41-45

Mulder WJM, Douma K, Koning GA, van Zandvoort MA, Lutgens E, Daemen MJ, Nicolay K, Strijkers GJ (2006) Liposome-enhanced MRI of neointimal lesions in the ApoE-KO mouse. Magn Reson Med 55:1170-1174

Nisman R, Dellaire G, Ren Y, Li R, Bazett-Jones DP (2004) Applications of quantum dots as probes for correlative fluorescence, conventional, and energy-filtered transmission electron microscopy. J Histochem Cytochem 52:13-18 
Ohno M, Takemura G, Ohno A, Misao J, Hayakawa Y, Minatoguchi S, Fujiwara T, Fujiwara H (1998) Apoptotic myocytes in infarct area in rabbit hearts may be oncotic myocytes with DNA fragmentation: analysis by immunogold electron microscopy combined with in situ nick end-labeling. Circulation 98:1422-1430

Paigen B, Morrow A, Holmes PA, Mitchell D, Williams RA (1987) Quantitative assessment of atherosclerotic lesions in mice. Atherosclerosis 68:231-240

Pinzani P, Orlando C, Pazzagli M (2006) Laser-assisted microdissection for real-time PCR sample preparation. Mol Asp Med 27:140 159

Plattner H (ed) (1989) Electron microscopy of subcellular dynamics. CRC Press, Boca Raton

Pozarowski P, Holden E, Darzynkiewicz Z (2006) Laser scanning cytometry: principles and applications. In: Taatjes DJ, Mossman BT (eds) Methods in molecular biology, vol 319: cell imaging techniques: methods and protocols. Humana Press Inc., Totowa, pp 165-192

Radmacher M, Fritz M, Kacher CM, Cleveland JP, Hansma PK (1996) Measuring the viscoelastic properties of human platelets with the atomic force microscope. Biophys J 70:556-567

Rand JH, Wu XX (1999) Antibody-mediated disruption of the annexin- $\mathrm{V}$ anticoagulant shield: a new mechanism for thrombosis in the antiphospholipid syndrome. Thromb Haemost 82:649-655

Rand JH, Wu X-X, Quinn AS, Chen PP, McCrae KR, Bovill EG, Taatjes DJ (2003) Human monoclonal antiphospholipid antibodies disrupt the annexin A5 anticoagulant shield on phospholipid bilayers. Evidence from atomic force microscopy and functional assay. Am J Pathol 163:1193-1200

Rand JH, Wu X-X, Quinn AS, Chen PP, Hathcock JJ, Taatjes DJ (2008) Hydroxychloroquine directly reduces the binding of antiphopholipid antibody- $\beta 2$-glycoprotein I complexes to phospholipid bilayers. Blood (submitted)

Reichlin T, Wild A, Durrenberger M, Daniels AU, Aebi U, Hunziker PR, Stolz M (2005) Investigating native coronary artery endothelium in situ and in cell culture by scanning force microscopy. J Struct Biol 152:52-63

Rice JH (2007) Beyond the diffraction limit: far-field fluorescence imaging with ultrahigh resolution. Mol BioSyst 3:781-793

Ruska E (1980) The early development of electron lenses and electron microscopy (translated by T. Mulvey). S. Hirzel Verlag, Stuttgart

Rust MJ, Bates M, Zhuang X (2006) Sub-diffraction-limit imaging by stochastic optical reconstruction microscopy (STORM). Nat Meth 3:793-795

Sabatini DD, Bensch KG, Barrnett RJ (1963) Cytochemistry and electron microscopy. The preservation of cellular ultrastructure and enzymatic activity by aldehyde fixation. J Cell Biol 17:19-58

Sanz J, Fayad ZA (2008) Imaging of atherosclerotic cardiovascular disease. Nature 451:953-957

Scherer NF (2006) Pointillist microscopy. Nat Nanotechnol 1:19-20

Schneider DJ, Hayes M, Wadsworth MP, Taatjes H, Rincon M, Taatjes DJ, Sobel BE (2004) Attenuation of neointimal vascular smooth muscle cellularity in atheroma by plasminogen activator inhibitor type I (PAI-1). J Histochem Cytochem 52:1091-1099

Shroff H, Galbraith CG, Galbraith JA, Betzig E (2008) Live-cell photoactivated localization microscopy of nanoscale adhesion dynamics. Nat Meth 5:417-423

Sit PS, Marchant RE (1999) Surface-dependent conformations of human fibrinogen observed by atomic force microscopy under aqueous conditions. Thromb Haemost 82:1053-1060

Sobel BE (1999a) The potential influence of insulin and plasminogen activator inhibitor type- 1 on formulation of vulnerable atherosclerotic plaques associated with type 2 diabetes. Proc Assoc Am Phys 111:313-318
Sobel BE (1999b) Increased plasminogen activator inhibitor-1 and vasculopathy: a reconcilable paradox. Circulation 99:2496-2498

Sobel BE, Taatjes DJ, Schneider DJ (2003) Intramural plasminogen activator inhibitor type-1 and coronary atherosclerosis. Arterioscler Thromb Vasc Biol 23:1979-1989

Sobel BE, Tarikuz Zaman AKM, Budd RC, Schneider DJ, Taatjes DJ (2008) Attenuation of apoptosis and the eye of the beholder. Coron Artery Dis 19:55-58

Stolle K, Weitkamp B, Rauterberg J, lorkowski S, Cullen P (2004) Laser microdissection-based analysis of mRNA expression in human coronary arteries with intimal thickening. J Histochem Cytochem 52:1511-1518

Storch KN, Taatjes DJ, Bouffard NA, Locknar S, Bishop NM, Langevin HM (2007) Alpha smooth muscle actin distribution in cytoplasm and nuclear invaginations of tissue connective tissue fibroblasts. Histochem Cell Biol 127:523-530

Taatjes DJ, Palmer CJ, Pantano C, Buder-Hoffmann S, Cummins A, Mossman BT (2001a) Laser-based microscopic approaches: application to cell signaling in environmental lung disease. BioTechniques 31:880-894

Taatjes DJ, Quinn AS, Jenny RJ, Hale P, Bovill EG, McDonagh J (1997a) Tertiary structure of the hepatic cell protein fibrinogen in fluid revealed by atomic force microscopy. Cell Biol Int 21:715726

Taatjes DJ, Schneider DJ, Bovill EG, Sobel BE (2001b) Microscopybased imaging of the pathogenesis of cardiovascular disease. Microsc Anal 50:21-23

Taatjes DJ, Sobel BE, Budd RC (2008) Morphological and cytochemical determination of cell death by apoptosis. Histochem Cell Biol 129:33-43

Taatjes DJ, Wadsworth M, Absher PM, Sobel BE, Schneider DJ (1997b) Immunoelectron microscopic localization of plasminogen activator inhibitor type 1 (PAI-1) in smooth muscle cells from morphologically normal and atherosclerotic human arteries. Ultrastruct Pathol 21:527-536

Taatjes DJ, Wadsworth MP, Schneider DJ, Sobel BE (2000) Improved quantitative characterization of atherosclerotic plaque composition with immunohistochemistry, confocal fluorescence microscopy, and computer-assisted image analysis. Histochem Cell Biol 113:161-173

Taatjes DJ, Wadsworth MP, Tarikuz Zaman AKM, Schneider DJ, Sobel BE (2007) A novel dual staining method for identification of apoptotic cells reveals a modest apoptotic response in infarcted mouse myocardium. Histochem Cell Biol 128:275-283

Tarikuz Zaman AKM, Fujii S, Schneider DJ, Taatjes DJ, Lijnen HR, Sobel BE (2007) Deleterious effects of lack of cardiac PAI-1 after coronary occlusion in mice and their pathophysiologic determinants. Histochem Cell Biol 128:135-145

Takemura G, Fujiwara H (2006) Morphological aspects of apoptosis in heart diseases. J Cell Mol Med 10:56-75

Trogan E, Choudhury RP, Dansky HM, Rong JX, Breslow JL, Fisher EA (2002) Laser capture microdissection analysis of gene expression in macrophages from atherosclerotic lesions of apolipoprotein E-deficient mice. Proc Natl Acad Sci (USA) 99:2234-2239

Wadsworth MP, Sobel BE, Schneider DJ, Taatjes DJ (2002) Delineation of the evolution of compositional changes in atheroma. Histochem Cell Biol 118:59-68

Wadsworth MP, Sobel BE, Schneider DJ, Tra W, van Hirtum H, Taatjes DJ (2006) Quantitative analysis of atherosclerotic lesion composition in mice. In: Taatjes DJ, Mossman BT (eds) Cell Imaging techniques: methods in molecular biology, vol 319. Humana Press, Totowa, pp 137-152

Weisel JW (2008) Enigmas of blood clot elasticity. Science 320:456457 